\title{
Health Status, Financial Consciousness and Rural Households' Credit Constraints
}

\author{
Chang Sheng $\mathrm{Li}^{12 \mathrm{a}}$ and Wen Qi Zhang ${ }^{1 \mathrm{~b}}$ \\ ( ${ }^{1}$ College of Economy, Fujian Agriculture and Forestry University, Fuzhou, 350002 \\ ${ }^{2}$ Reseach Center of "Sannong", Jiangxi Agricultural University, Nanchang, 330045 )

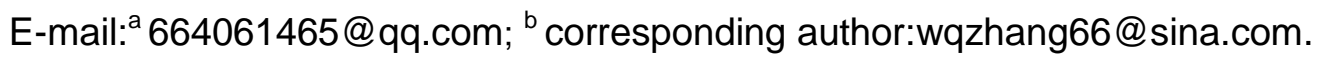

Keywords: Health Status; Financial Consciousness; Credit Constraints; Rural Households; South China.

\begin{abstract}
Since credit is assumed as a critical vehicle for poverty alleviation, it is necessary to examine what are the key factors affected rural households' credit constraints. This paper investigates the determinants affecting the rural households' credit constraints in Jiangxi province of the southern China. Data used in this paper was investigated from a random survey of 743 rural households, conducted in the summer holiday in 2013. The statistical analysis of the sample indicates that $54.9 \%$ of the respondents were credit constrained. The results of the Probit model imply that the rural households' health status has a positive and significant impact on their credit constraints while financial consciousness negatively and significantly affect their credit constraints. These findings indicate that improving the income of farmers requires the improvement of credit accessibility of the rural households.
\end{abstract}

\section{Introduction}

The great economic success in China is mainly attributed to the development of the financial system. Financial service developed dramatically over the last years, but in most rural areas, credit constraint is still universal and poverty levels remain significant (John N.N., Ugoani.2013, Bruton R.M,,Kenny D.A. 2011). Formal credit constraint is one of the vital factors to the growing income gap between the urban and rural residents and has significant adverse effect on farm output (Beck at al. 2009). For farmers, especially the poor farmers, formal credit constraint has a significant negative impact on their family income and welfare (Boucher et al. 2006). Loans form formal financial institutions are considered to be crucial for rural households to smooth their consumption and promote their production (Kochar. 1997; Boucher et al. 2006, 2005). The purpose of this paper is to explore the determinants of the rural households' credit constraints. We focus on this issue because formal credit is supposed to be a strategy core of the rural credit policy (CHEN dong, etc., 2013). And rural informal loans are hard to satisfy the farmers' long term financial demand. As a result, farmers are still looking forward to obtaining formal loans (Jiao Jin-Pu etc., 2013; HUANG zu-hui, etc., 2009).

The previous literatures show that there are many factors such as unstable income and high transaction cost (Tiamiyu et al. 2010) affect the accessibility of the formal loans. Unlike most of the existing literatures, we analyze the critical factors of the credit constraint from the perspective of health status and financial consciousness of the rural households to explore how health and financial consciousness affect rural households' credit appointment. As a capital good of the rural households, health status can improve or reduce their productive ability. It will directly affect their income and latent repayment rate. Financial consciousness will help the farmers know more about either the financial institutions or their clerk and productions. Improving financial consciousness is a key way to low the credit risk and cost. A Probit model is used to test their influential direction of the key 
variable. In the second step, average marginal effects of the variables are calculated to reveal their influential degree.

\section{Empirical model and variables}

Empirical model. We use a Probit model to explore the critical determinants of the rural households' formal credit constraints:

$$
\begin{aligned}
\operatorname{prob}(Y=1 \mid X)= & \operatorname{prob}\left(Y^{*}>0 \mid X\right)=\operatorname{prob}\{[u>-(\alpha+\beta X) \mid] \mid X\} \\
& =1-\Phi[-(\alpha+\beta X)]=\Phi[(\alpha+\beta X)]
\end{aligned}
$$

Where $X$ represents these observed independent variables. Critical independent variables include rural households' health status and financial consciousness. Health status was evaluated by the head of the rural households themselves and 4 levels were nominated (very good $=1$; good $=2$; normal $=3$ and bad=4). There are two proxies for financial consciousness. One is measured by that whether the rural households' members own a bank card or not (The variable name in the model is $A C A R$ ). Another one is the cumulative total of times of family head saves money in financial institutions $(S A N U)$. Control variables are character of the rural households including age, education level of the head of the households and so on and regional variables.

In this Probit model, $Y^{*}$ is a vector of the latent variable that is not observed for values less than zero or more than zero. when $Y^{*}>0, \mathrm{Y}$ is equal to 1 which means the farmer household was credit constrained. Otherwise $\mathrm{Y}$ is equal to 0 which means that the farmer household was not credit constrained. $\Phi(\bullet)$ is a cumulative distribution function.

$$
Y= \begin{cases}1, & \text { when } Y^{*}>0, \\ 0, & \text { when } Y^{*}<0,\end{cases}
$$

Data source. Totally 918 samples used in this paper were investigated from a random survey in 34 counties from Ganzhou, Fuzhou and Ji'an city in Jiangxi province in south China. Sample selection is geographically based: Ganzhou city is located in the southern of the province, Ji'an city in the middle while Fuzhou city in the north. About $46.8 \%$ of the total samples was selected from Ganzhou city, and $28.4 \%$ and $24.7 \%$ were from Ji'an and Fuzhou city respectively. The contents of the survey include the characteristics of rural households, demand and the satisfaction of the credit. 916 questionnaires were collected. But some 44 questionnaires were not effective because some key data were missing. In addition, 129 sample rural households had gone to big cities for a work. Their lands were cheaply rent to other farmers. Then 743 samples were used to explore the impact of health status and financial consciousness on their credit constraints.

Variables description. the dependent variable. The statistics of the independent variables are reported as follows. About 54.9\% of the whole sample rural households were directly suffered from formal credit constraints. Among these farmers, 63\% (257/408) were credit constrained because of transaction cost or credit risk. 87 (accounting for 21.3\%) rural households had applied for a loan but were totally withdrawn by the financial institutions. There were 253 (accounting for $34 \%$ ) rural households had applied for a loan but were partly rejected by the financial institutions. In other words, 75.5\% (253/335)of the farmers had got loans from formal financial institutions. 82 farmers had no demand for formal credit because they do not want to pay the interest for the banks. These results show that the reason why farmers were credit constrained lied in the demand of the farmers instead of the banks. It is necessary and important for the farmers to increase their financial consciousness.

the independent variables. The descriptive statistics of the independent variables are shown in 
Table 1. In our sample, 12.38\% (92/743) rural households' health status is in the state of "very good". Their health status of "good", "normal" and "bad" hold the proportion of $38.36 \%, 45.76 \%$ and $3.50 \%$ respectively. About39.84\% (296/743) rural households own at least one bank card while $60.16 \%$ (447/743) has no any bank card. Most farmers made the financial transaction by deposit book because they can't use the card freely. It is very hard for the bank clerk to teacher them use the card correctly. There are even 405 heads of the rural households didn't save their money in the bank in the last year. The average times of the head save their money in a bank per month is only 0.3419 . The financial activity should be improved dramatically in the future.

Survey result shows the average age of the farmers was 45.5 years implying that farmers were still in their productive years. 85.6\% of the farmers only got their education in junior high school. Only 20 farmers were educated from colleges, 18 of them were not credit constrained which meant that education level had a great influence on the formal credit accessibility. About $10 \%$ of the farmers joined some kinds of cooperatives. The average farming experience is 18.3 years.

Table 1 Variable Selection and Descriptive Statistic

\begin{tabular}{llcccc}
\hline \multicolumn{1}{c}{ Var. } & \multicolumn{1}{c}{ definition } & Mean & Std Dev & Min & Max \\
\hline CRED & Credit constraint=1,otherwise=0 & 0.5491 & 0.4979 & 0 & 1 \\
GEN & Gender of head (M = 1, F=0) & 0.9392 & 0.2391 & 0 & 1 \\
AGE & Years of the age of the head & 45.5006 & 8.2039 & 24 & 65 \\
EDU & Years of formal education & 1.8830 & 0.7501 & 1 & 4 \\
EXPE & Years of experience of farming & 18.3109 & 10.1308 & 3 & 60 \\
HEAL & Discrete variable from 1 to 4 & 3.1857 & 0.7808 & 1 & 4 \\
POLI & Political participation & 0.3727 & 0.4838 & 0 & 1 \\
COOP & Number of the cooperatives & 0.0986 & 0.3321 & 0 & 3 \\
DIST & Measured in kilometers & 3.3507 & 3.4431 & 1 & 40 \\
LAND & Measured in MU & 4.8532 & 3.4752 & 0.2 & 30.4 \\
TOIN & Total income (RMB yuan) & 9279.02 & 21133.66 & 107.2 & 303120 \\
LNIN & Logarithmic total income & 7.7657 & 1.4777 & 4.6747 & 12.6219 \\
ACAR & Weather a farmer own a bank & 0.6016 & 0.5296 & 0 & 1 \\
& card(yes=1,no=0) & & & & \\
SANU & Average times of saving money & 0.3419 & 0.4914 & 0 & 2 \\
& in a bank per month & & & & \\
\hline
\end{tabular}

\section{Results and discussion}

In this section, we examine the determinants of the credit constraints of the rural households by maximum likelihood method in STATA12. The results of the probit estimations are reported in Table 2. The value of the Log likelihood and Prob $>\mathrm{chi}^{2}$ show that the model fits well.

The coefficients and the $\mathrm{P}>|\mathrm{z}|$ values show clearly that the critical variable of the rural household' health status had positive and significant impact on their credit constraints. Since $A C A R$ and $S A N U$ are proxy variables of the rural households' financial consciousness, these coefficients and the $\mathrm{P}>|\mathrm{z}|$ values reveal that financial consciousness was significantly negative to the farmer household' credit constraints. Anymore, there are some other variables such as AGE, POLI, FUZH and JIAN are significantly negative to the credit constraints. Some variables such as GEN,EDU,EXPE,LAND and LNIN have no significant influence on the farmer households' credit constraints.

(1) " $m u$ " is a unit of the land area used in Chinese. 1 acre $=6.07 \mathrm{mu}, 1 \mathrm{MU}=666.7 \mathrm{~m}^{2}$. 
Table 2 Estimated Results of the Model

\begin{tabular}{|c|c|c|c|c|c|c|c|c|c|}
\hline \multicolumn{7}{|c|}{ Probit regression } & \multicolumn{3}{|c|}{ Number of obs $=743$} \\
\hline & \multirow[b]{3}{*}{ Coef. } & \multirow{2}{*}{\multicolumn{5}{|c|}{$\begin{array}{l}\text { chi2 }(14)=222.3 \\
\text { Log likelihood }=-400.25042\end{array}$}} & \multirow{2}{*}{\multicolumn{3}{|c|}{$\begin{array}{l}\text { Prob }>\text { chi2 }=0.0000 \\
\text { Pseudo R2 }=0.2174\end{array}$}} \\
\hline & & & & & & & & & \\
\hline & & Std. E. & $z$ & $\mathrm{P}>|\mathrm{z}|$ & & Coef. & Std. E. & $z$ & $P>|z|$ \\
\hline GEN & 0.1103 & 0.2180 & 0.51 & 0.613 & DIST & 0.0136 & 0.0051 & $2.65^{* * *}$ & 0.008 \\
\hline AGE & -0.0151 & 0.0063 & $-2.39 * *$ & 0.017 & LAND & -0.0021 & 0.0157 & -0.13 & 0.894 \\
\hline EDU & 0.0001 & 0.0740 & 0.00 & 0.999 & LNIN & -0.0253 & 0.0411 & -0.62 & 0.538 \\
\hline EXPE & 0.0032 & 0.0639 & 0.05 & 0.960 & ACAR & -0.9509 & 0.1067 & $-8.91 * * *$ & 0.000 \\
\hline HEAL & 0.0134 & 0.0054 & $2.50^{* *}$ & 0.013 & SANU & -1.1789 & 0.1145 & $-10.29 * * *$ & 0.000 \\
\hline POLI & -0.3128 & 0.1477 & $-2.12^{* *}$ & 0.034 & FUZH & -1.2305 & 0.1705 & $-7.22 * * *$ & 0.000 \\
\hline COOP & -0.1834 & 0.1613 & -1.14 & 0.255 & JIAN & -0.4221 & 0.1388 & $-3.04 * * *$ & 0.002 \\
\hline cons & 0.6499 & 0.5048 & 1.29 & 0.198 & & & & & \\
\hline
\end{tabular}

Note: ***Significant at $1 \%$ level, ** Significant at $5 \%$ level and $*$ Significant at $10 \%$ level.

The estimates reported in Table 2 show us the influential directions (positive or negative) .But we should get the influential extent of the independent variables on the dependent variable by calculating the marginal effect of the variables. There are three kinds of marginal effect and the results are greatly different. For the policy analysis, the average marginal effect will be more meaningful compared with the marginal effect on the level of the means and the marginal effect on the representative samples.

We reported the average marginal effects in Table 3. Farmer households' health statue (HEAL) is positively and significantly related to their credit constraints. The probability of credit constraint is increased by $0.39 \%$ among rural households when their health status was dropped to a lower level. The coefficient and the $\mathrm{P}>|\mathrm{z}|$ value of the $A C A R$ reveals that the probability of credit constraint for the rural households that own at least one bank card is lower by $29.4 \%$ compared to those rural households who have no any bank card. The average marginal effect of the coefficient of $S A N U$ implies that the probability of credit constraint for the rural households will decrease at least $39.48 \%$ when the family members increase every one time in a month to save their money in the formal institutions.

Besides these key variables, some control variables also significantly affected the rural households' credit constraint. The age of the head of the rural households increase every one year, the probability of credit constraint will decrease $0.46 \%$. The possibility of credit constraints will increase by $0.40 \%$ when the minimum distance between farmers and the financial institutions increase every one kilometer. Furthermore, the probability of credit constraint is lower among rural households that located in Fuzhou and Ji'an cities by $39.39 \%$ and $13.42 \%$ respectively than those rural households in Ganzhou city.

Table 3 Average Marginal Effects of the Total Variables

\begin{tabular}{llllllllll}
\hline & dy/dx & Std.E. & $\mathbf{z}$ & $\mathbf{P}>|\mathbf{z}|$ & & dy/dx & Std. E. & $\mathbf{z}$ & $\mathbf{P}>|\mathbf{z}|$ \\
\hline GEN & 0.0342 & 0.0670 & 0.51 & 0.610 & DISTA & 0.0040 & 0.0016 & $2.61^{* * *}$ & 0.009 \\
AGE & -0.0046 & 0.0019 & $-2.39^{* *}$ & 0.017 & LAND & $-4.66 \mathrm{e}-06$ & 0.0048 & -0.00 & 0.999 \\
EDU & 0.0011 & 0.0226 & 0.05 & 0.960 & LNIN & $-1.68 \mathrm{e}-06$ & $8.84 \mathrm{e}-07$ & -1.90 & 0.057 \\
EXPE & 0.0017 & 0.0196 & 0.09 & 0.932 & ACAR & -0.2940 & 0.0278 & $-10.58^{* * *}$ & 0.000 \\
HEAL & 0.0039 & 0.0016 & $2.44^{* *}$ & 0.015 & SANU & -0.3648 & 0.0274 & $-13.30^{* * *}$ & 0.000 \\
POLI & -0.0125 & 0.0035 & -0.04 & 0.072 & FUZH & -0.3939 & 0.0449 & $-8.78^{* * *}$ & 0.000 \\
COOP & -0.0449 & 0.0496 & 0.90 & 0.366 & JIAN & -0.1342 & 0.0416 & $-3.23^{* * *}$ & 0.001 \\
\hline
\end{tabular}

Note: ***Significant at 1\% level, ** Significant at 5\% level and * Significant at $10 \%$ level. 


\section{Conclusions}

Lack of financial support, especially credit is considered one of the critical reasons for rural households to live a poor life. The results of the econometric model employed in this paper revealed that the rural households' health status would positively affect their credit constraints. The probability of credit constraint is increased by $0.39 \%$ for rural households when their health status was dropped to a lower level. If their health status deteriorated, their productivity would decrease and their cost would increase which resulted in the amplification of the risk of loans. Encouraging farmers to maintain the good health status of their family members would help increase the accessibility of the loans from formal financial institutions. On the other hand, the findings of this study also showed that rural households' financial consciousness had a negative influential impact on their credit constraints. The probability of credit constraint for the rural households that own at least one bank card is lower by $29.4 \%$ compared to those rural households who have no any bank card. The probability of credit constraint for the rural households will decrease at least $39.48 \%$ when the family members increase every one time in a month to save or withdraw their money in the formal institutions. Improving rural households' financial consciousness is an effective measure to alleviate their credit constraints. Therefore financial institutions should give emphasis on the propaganda of financial knowledge, the promotion of the financial products and financial activities.

\section{Acknowledgements}

This work was financially supported by the National Funds of Social Science (No.12CGL022),National Natural Science Foundation of China(No.71263023), National Natural Science Foundation of China(No. 71063010), Funds for the Foundation of College's Key Research on Humanities and Social Science in Jiangxi province (No.JD1449) and Soft science planning project of Jiangxi province(No. 20141BBA10025).

\section{References}

[1] A .Kochar: Journal of Development Economics ,24(1997), p. 86.

[2]Beck,T. Demirguc-Kunt A. and Honohan, P. : The World Bank Research Observer. 24(2009),p. 119.

[3] Boucher, S., Guirkinger, C. and Trivelli C.: Economic Development and Cultural Change. 57(2006), p. 609.

[4]Bruton R.M,,Kenny D.A.: Journal of Personality and Social Psychology. 51 (2011), p.1173-1182

[5] Chen botian, Xia tian. The finance (academic version), 5(2013),p. 5-7. (in Chinese).

[6] CHEN dong, LIU jin-dong: Financial research.6(2013), p. 160.(in Chinese).

[7] Cheng yu, Luo Dan. The world economy wenhui.2(2012),2,pp. 69-80. (in Chinese) .

[8]HUANG zu-hui, LIU xi-chuan: Journal of economic research. 4(2009), p. 116.(in Chinese).

[9] John N.N., Ugoani. International Journal of Financial Economics, 3(2013),p. 93-102 .

57(2006), p. 609. 
[10]Tiamiyu S.A., Akintola J.O., Rahji M..Agricultural Tropica et Subtropica.43(2010),p.134. 